intubation of the larynx, must be kept up. Artificial respiration can be first tri?d, but in this desperate condition there must not be more than a very few minutes' delay before direct massage of the heart is begun, because if delay is too long, even though the heart recover, the nervous system is damaged by prolonged oxrgen starvation, and the patient dies from this reason. When the heart gradually fails from overdosage, artificial respiration, conducted by squeezing the chest rhythmically, will recover it by bringing fresh blood into the coronary arteries and through the lungs, and so getting rid of the chloroform and admitting a supply of oxygen. MacWilliam finds that injection of 0.5 gram per kilogram of body weight of urethane beforehand prevents fibrillation in animals during chloloform anaesthesia.

\title{
Ether.
}

When ether is the anaesthetic, the symptoms of poisoning are in general the same, but fibrillation or failure of the heart from overdosage is much more unlikely because of the far lower toxicity of the drug. The anaesthetic partial pressure of ether is 3.7 to 4 per cent. of an atmosphere. The solubility of the brain tissue for ether is practically the same as that of blood. Large pulmonary ventilation and rapid blood flow through the brain results in quick anaesthesia.

In every operating theatre there should be available a cylinder containing oxygen and 5 per cent. carbon dioxide. By using this with ether at the beginning of anaesthetization deep breathing is obtained and quicker narcosis. A lower percentage of ether can be used and less irritation of the bronchial mucosa caused. After prolonged ether anaesthesia the colour and fullness of the veins in the skin are restored by breathing this mixture (Yandell Henderson and Haggard). By using it alone after operation the decp breathing excited by the carbon dioxide washes ether out of the body and introduces oxygen; this greatly lessens the after-effects and helps recovery. It is
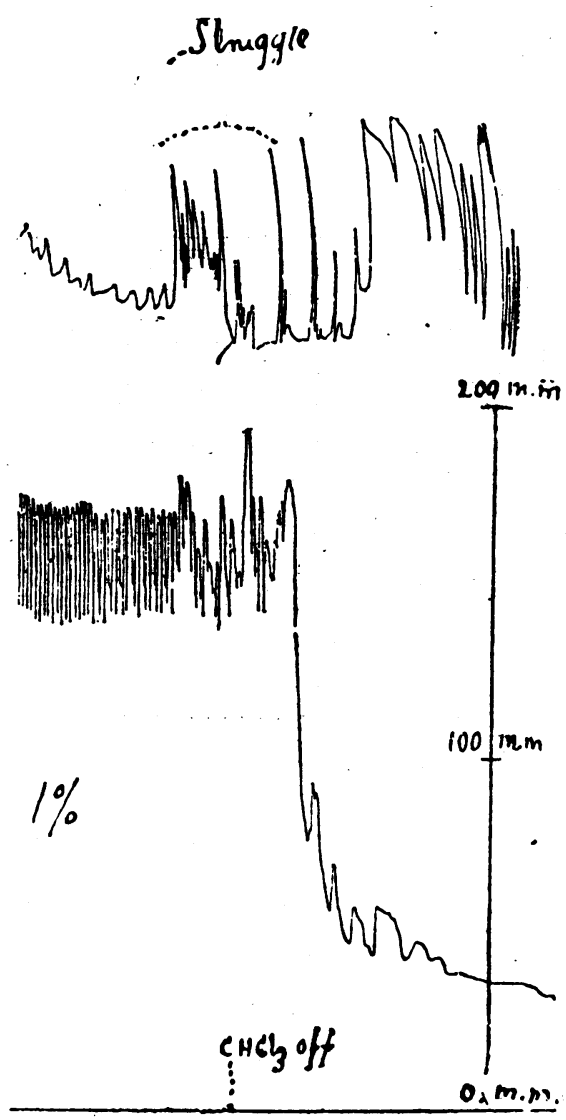

F1G. 5.-Ventricular fibrillation initiated during a i.t of :truggling in a cat under light chloroform anaestheeia. Upper record : respiratory. Lower marked in seconds. The period of etruggling i indicated by the irregular respiration record within the dotted bracket. The cardiac collaps is followed by intense dyspnoeic gasps. The hear was inspected immediately on the cessation of respiration, and the ventricles were seen to b fibrillating vigorously. (The declination on the
left of the respiratory record is accidental.) (Levy.) mine on the respiratory centre.

In animals chloralese or urethane $(6 \mathrm{c.cm}$. of a $8 j$ per cent. solution per $\mathrm{kg}$. body weight) injected subcutaneously, pressure, and is very convenient.

Ether in oil introduced into the rectum, after washing this out, produces anaesthesia which may be long lasting. This plan has been suggested for use when no help is at hand to give this anaesthetic by inhalation.

\section{Local Anaesthesia.}

Turning to local anaesthesia, we know that cocaine is a general protoplasmic poison, and its poisoning action is exerted on the central nervous system, the symptoms being excitement, convulsions passing into coma, and death from asphyxia. The blood vessels are contracted, blood pressure raised considerably, the heart also being accelerated in the stage of excitement. A local contraction of the vessels is caused by the application of cocaine. The artificial alkaloids used as a substitute for cocaine are much less poisonous, and have not the same constricting effect on the blood vessels. Thus novocain is quickly destroyed in the liver, and is for this reason much safer. Adrenaline increases the toxicity of cocaine according to the findings of the committee of the American Medical Association. This committee believes that local anaesthetics may be applied safely in the following concentrations and total amounts: Cocaine in the mouth 5 per cent., in the nose up to 10 per cent., and in total amounts of from 10 to 15 minims containing at most 1 to 1.5 grain. In the eye not over 5 per cent. should be used. In the larynx 10 per cent. and not over 15 minims, containing 1 to 1.5 grain. Novocain in concentrations not greater than 1 per cent. Adrenaline or epinephrin should not be used with cocaine in concentrations greater than 1 in 10,000 , and not more than 10 minims of this-with novocain up to $1 \mathrm{mg}$. of adrenaline-is allowed; but even this

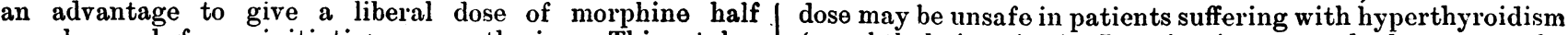
an hour before initiating anaesthesia. This takes (exophthalmic goitre). In poisoning cases the heart must be away anxiety, lessens the period of excitement, decreases massaged by artificial respiration to keep up the circulation pain after anaesthesia, and is an excellent preventive through the liver; the injection of any other drugs is of shock. The breathing of the oxygen $\mathrm{CO}$, mixture probably useless, and may increase the danger.

RECOVERY AFTER MASSAGE OF THE HEART. BY

W. GIRLING BALL, F.R.C.S.Evg., BURGEON WITH CHARGE OF OUT-PATIENTS, ST. BARTHOLOMEW'S HOSPITAL.

The following case is one of considerable interest, as it illustrates the value of massage of the heart when it has ceased to beat during the performance of a major surgical operation.

\section{History.}

A man, aged 50, was admitted under my care to St. Bartholomew's Hospital on September 28th, 1925. His story was as follows : In October, 1913, he was admitted to the hospital with perforation of a gastric ulcer, which was sutured by myself; a posterior gastro-enterostomy was performed at the same time. $\mathrm{He}$ made an uninterrupted recovery, and departed for West Africa, where he has been living up to this time. In 1916 he had a bad attack of dysentery. In 1918 he began to have a grinding pain in the neighbourhood of the umbilicus on the left side of the abdomen, extending towards the left iliac fossa; the pain usually came on about three hours after food and lasted for an hour or two. From time to time this pain would disappear for a period of two or three months; since 1920, however, it had gradually become more persistent, and as a result thereof his life had become very miserable.

On admission to hospital he looked fairly well, but his facies suggested that of a man suffering from constant pain. His teeth had all been removed, so that oral sepsis was excluded as a cause of his symptoms. There was well marked tenderness to the left of the middle line in the epigastric region; over this point of tenderness there was an area of superficial hyperaesthesia. His pain was only partially relieved by placing him on a convalescent diet. The character of the pain suggested that he might have a gastro-jejunal ulcer, and I decided to explore his abdomen to settle this point.

Operation.

On October 2nd he was anaesthetized by the endotracheal gas-oxygen-ether method. No ulcer or scar could be found in the region of the site of the old perforation, but there was thickening around the gastro-jejunal junction on the proximal side of the stoma, which was involving the transverse colon and was obviously the site of a gastro-jejunal ulcer. The jejunum was divided proximally and distally to the stoma and an end-to-end anastomosis made. The transverse mesocolon was then separated from the anastomosis and its adhesion to the colon divided. The ulcer had not actually perforated into the colon; the point of 
attachment, however, was very thin, and as a precaution was sewn over; the hole in the transverse mesocolon was closed. The omentum and the gastro-hepatio omentum were then separated Irom their attachments to the stomach.

\section{Massage of the Heart.}

At this stage the patient suddenly stopped breathing and his heart ceased to beat. His head was lowered and oxygen only was passed down the intratracheal tube under intermittent pressure. The stomach was rapidly separated between clamps, from the duodenum and thrown over to the left side of the abdomen. The heart was then gently massaged through the diaphragm at the rate of about sixty to the minute, artificial respiration being kept up meanwhile; 10 minims of 1 in 1,000 adrenaline were injected into the heart muscle through the chest wall. Three minutes elapsed before any sign of heart movements was noticed, when a single: forcible contraction was felt; this was followed by fibrillary twitchings for about ten seconds, and was then succeeded by a series of regular, rapid, feeble beats until gradually it beat with its normal rhythm but at rather until gradually it beat with its normal rhythm, but at rather a rapid rate. Shortly after the heart began to beat the patient commenced to breathe. proceeded with, a Billroth No. 1 anastomosis being made, after proceeded with, a Billroth No. 1 anastomosis being made, after jejunal anastomosis. This operation took forty minutes to complete, the anaesthesia being continued with pure nitrous oxideoxygen through the tracheal catheter.

In the excised portion of stomach there was no sign of the old gastric ulcer, but there was a small gastro-jejunal ulcer, a third of an inch in diameter, surrounded by an indurated wall, on the left side of the junction.

\section{Aftcr-History.}

The patient was returned to bed with hot-water bottles and was given rectal injections of saline and glucose. His pulse rate remained very rapid and its volume was very small, but at the end of three hours he showed signs of recovery and became extremely restless. His temperature remained normal, but the respiratory and pulse rates were raised for about ten days. Some suppuration took place in the abdominal wall.

Ten days after the operation he had a severe haematemesis, which was followed by another two days later. He was put on a modified Lenhartz diet. From this time onwards he began to improve and made an uninterrupted recovery. When discharged from the hospital, on November 21st, he was taking a light diet, was free from symptoms, and was putting taking a light diet, remained well, without any furth putting on weight. He has remain symptoms. The wound was healed and the pulse, temperature, and respiratory rates were normal. A barium meal, given just prior to his departure from the hospital, demonstrated that the new channel was working Eatisfactorily. He saw me on March 17th, 1926, stating that he had no symptoms, was quite fit, and was leaving for Uganda.

There are some points worthy of comment in this case, apart from the recovery of the patient. Up to the moment of his collapse there was no indication that this was about to happen; in fact, only just prior to the moment I had commented to the anaesthetist that he was standing the operation well. In the second place, it is surprising that, in addition to obtaining a recovery of the heart's action, it was possible for me to complete the operation, which took at least another forty minutes. Naturally, the completion of the operation was carried out under a severe stress, and it is my belief that the haematemeses were of the nature of secondary haemorrhages, probably due to faulty technique.

e. Cases of recovery after massage of the heart are, of course, on record, although in many instances failure occurs; the patients survive the operation, but either never regain consciousness ar die of some lung complication. In some cases the abdomen has required to be opened in order to perform necessary manipulations. In this case, however, although some preliminary manœuvres had to be effected, owing to the nature of the operation in hand, in order to reach the diaphragm, very little time was lost before massage was commenced. In addition, it is possible that recovery was naturally aided by the presence of a tracheal catheter in position at the moment of cardiac failure, which permitted the immediate inflation of the lungs with oxygen under pressure; so that while the heart was being massaged the artificial circulation provided sufficient oxygenated blood to the brain to obviate the cerebral anaemia which usually proves fatal in these cases. The production of a pink coloration of the patient's face with each artificial pulsation of the heart was a very noticeable feature. The diaphragm was not incised, but the heart was squeezed by the right hand inserted under the diaphragm while the heart was pressed against the anterior chest wall. So far as could be observed, both before and after the operation there was no heart lesion.

I I am indebted to my house-surgeon, Mr. Dodd, and to the anaesthetist, Mr. Hewer, for so ably assisting me to bring about the man's recovery.

\section{Xumlexar Pertures ox ENDOCARDITIS. \\ - BY}

Gir ThOMAS HORDER, Bт., K.C.V.O., M.D.q PHYSICIAN TO ST. BARTHOLOMEW'S HOSPITAL.

LECTURE III.*

I PRopose now to deal with the anatomical and bacteriological parts of my subject, and then with considerations of diagnosis, pathogenesis, and treatment.

State of THE ENDOCARDIUM BEFore INFECTION.

The state of the valves prior to the onset of septic endocarditis is an important point. In my original series of 118 post-mortem examinations in 150 cases I found evidence of old valve disease in 80 per cent. The figures of other observers approximate very near to this. But it is to be noted that this figure refers to acute and chronic cases when taken together. If wo consider acute cases alone the figure is undoubtedly much smaller. If we take the series of cases of ex-soldiers by themselves we find it smaller still. Thus, out of 13 autopsies in this class Starling found scarring from old rheumatic disease in one only. Carey Coombs's experience is much the same. The inclusion of 20 cases of ex-service men explains why, in a second series of 162 cases at St. Bartholomew's Hospital, the figure is only 50 per cent. You, Sir, in the course of the Lumleian Lectures given by you in 1920, stated that, despite the prevalence of sepsis in the wounded during the great war, infective endocarditis was uncommon; that a number of acute and rapidly fatal cases of the disease occurred in men in whom no primary source of infection could be found post mortem; and that in these cases the infection had attacked healthy valves. Summing up, therefore, it may be said that in acute cases generally, and in the chronic ex-service cases, there is a notable absence of pre-existing valvular disease; in chronic civilian cases there is a marked preponderance of pre-existing valvular disease. It has perhaps been too readily assumed that the nature of the pre-existing valve damage found at autopsy is generally rheumatic in origin. Care must be taken, as Libman has pointed out, to distinguish the residues of rheumatic infection from the residues of an old septio endocarditis, since it is now known that this latter process may recur after years of apparent freedom from active infection. The patient's history is therefore of great importance in judging the nature of cicatricial and of sclerotic changes in the valves. Since pericarditis is known to be quite rare in chronic septic endocarditis, evidence of this at autopsy is much in favour of old rheumatic infection. The type of myocardial disease, if this be present, may also assist in a correct interpretation of the findings.

Of the valves affected it is again important to distinguish acute from chronic cases, and civilian chronic cases from ex-service chronio cases. In acute cases the incidence of mitral and aortic disease is probably about equal. Of 34 such cases due to Streptococcus pyogenes Thayer found the aortic valve involved in 20 cases, the mitral in 26 . Gonococcal infection, however, tends to attack the aortic valve by precedence. Thayer's cases, forming the fullest series of which we have details, showed 66 per cent. aortic and only 19 per cent. mitral. There were right heart lesions as often as mitral in this infection. Of 40 cases of pneumococcal endocarditis, Thayer found the aortic cusps involved in 20 , the mitral in 13, and the valves on the right side of the heart in 7 only, thus disposing of the fallacy that pneumococcal infection is prone to attack the right heart chiefly. In chronic septic endocarditis, however, there is a preponderance of mitral infections in civilian cases, and a still greater preponderance of aortic cases in ex-soldiers,

\section{Mural Infection.}

Mural infection is, I believe, more common than is generally thought. I found instances of this condition in 52 per cent. of 118 pust-mortem examinations. Thayer's figure is as high as 84 per cent. in chronic cases. Auricular - Delivered before the Royal College of Physicians, London, on March 30th. 